\title{
Morphological and Physiological Traits that Explain Yield Response to Drought Stress in Miscanthus
}

\author{
Marta Malinowska ${ }^{+}(\mathbb{D}$, Iain Donnison $(1)$ and Paul Robson *(i) \\ Institute of Biological, Environmental and Rural Sciences, Aberystwyth University, Plas Gogerddan, \\ Aberystwyth SY23 3EE, UK; m.malinowska@qgg.au.dk (M.M.); isd@aber.ac.uk (I.D.) \\ * Correspondence: ppr@aber.ac.uk; Tel.: +44-(0)1970-823091 \\ + Current address: Center for Quantitative Genetics \& Genomics, Aarhus University, 4200 Slagelse, Denmark.
}

Received: 27 June 2020; Accepted: 12 August 2020; Published: 14 August 2020

\begin{abstract}
Miscanthus is a high yielding perennial grass capable of high biomass yields with low inputs. Traits associated with yield have been identified in miscanthus, but less is known about the traits associated with sustaining biomass production under drought stress. The commercial hybrid $M . \times$ giganteus and high yielding examples from the parental species $M$. sinensis and M. sacchariflorus were grown under well-watered and moderate drought conditions. Growth, morphology, physiology and phenotypic plasticity were analyzed. Functional data were parameterized and a matrix of traits examined for associations with yield, genotype and drought treatment. Phenotypic plasticity was determined, indexes were then calculated to determine the plasticity of trait responses. All genotypes assessed responded to moderate drought stress, and genotypic differences in yield decreased under drought. Genotypes with low tolerance exhibited greater plasticity than highly drought tolerant M. sinensis. In well-watered plants variance in yield was explained by a relatively simple empirical model including stem length and stem number, whereas under drought a more complex model was needed including the addition of leaf area and stomatal conductance data. This knowledge can help us to define ideotypes for drought tolerance and develop miscanthus varieties that sustain high yields across a range of environmental conditions.
\end{abstract}

Keywords: bioenergy; energy crops; miscanthus; drought; water use efficiency; phenotypic plasticity; modelling; resilience

\section{Introduction}

To produce sustainable biomass for the bioeconomy, crops are required, which can displace carbon-intensive feedstocks while also limiting any potential negative impacts [1]. Important characteristics of energy crops include high energy output to input ratios, a low requirement for agronomic interventions such as irrigation [2], an ability to grow on underutilized marginal land to minimize pressure on food production [3,4] and increasing opportunities for rural development and diversification [5]. It is, therefore, necessary to develop energy crops which exhibit high yields and resilience to environmental stresses. Drought, in particular, may be a factor in making land marginal and more generally is one of the most limiting factors affecting crop yield worldwide [6]. For example, the production of energy crops, under future climate change scenarios, will be limited in most regions of southern Europe [7]. Thus, for bioenergy crops, there is a need to improve abiotic stress tolerance and improve understanding of drought tolerance mechanisms [8,9]. The ability of plants to not only withstand drought but also efficiently produce biomass under moderate drought is important [10].

Miscanthus is a genus of $\mathrm{C} 4$ perennial grasses capable of high biomass production even in temperate regions and has a number of characteristics that make it an ideal crop for the renewable supply of energy and chemicals [2,11-13]. However, the yield is strongly linked to water availability, 
and many environments have limited water supply where otherwise irradiation and temperature are favourable for biomass production. Miscanthus though is largely undomesticated with considerable natural variation available for crop improvement [14-16]. Miscanthus is perennial and develops yield over a longer period than conventional annual grain crops, and as such, the importance of some trait-to-yield associations may be expected to be different. To test this, a large number of phenotypic traits associated with yield accumulation [17-20], and complex traits such as seasonal duration and harvestable yield [21-23] have been measured in diverse miscanthus populations. A number of studies have examined responses to, and genotypic variation in traits associated with, drought [24-29]. However, drought resistance in undomesticated miscanthus is the result of natural evolution and may not necessarily favour growth under stress but rather survival. Few studies have attempted to examine yield associations across a broad range of traits to help define ideotypes that sustain yield or improve yield resilience under drought. In this study we examined five high yielding and diverse miscanthus genotypes to determine how associations between yield and morphological and physiological traits changed between well-watered and drought conditions. The aim was to identify the traits that most contributed to the accumulation of higher biomass in optimal and in droughted conditions.

\section{Materials and Methods}

\subsection{Plant Material}

Five miscanthus genotypes were selected (Table S1) which were in the top $10 \%$ for biomass accumulation from a population of 47 diverse genotypes investigated in a drought stress study using phenomics [30]. The designations for genotypes have the same numerical suffix as reported in Kalinina et al. [13]: M. $\times$ giganteus a commercial triploid hybrid between $M$. sacchariflorus and $M$. sinensis [31] (WAT09); a triploid M. sinensis hybrid (Goliath) (WAT11), a diploid M. sacchariflorus $\times$ M. sinensis hybrid (WAT10); and two wild accessions of $M$. sacchariflorus (WAT03 and WAT04). The genotypes chosen were representative of two morphotypes, $M$. sacchariflorus types which morphologically tend to have large rhizomes and thick stems $[14,32]$ and $M$. sinensis types which tend to be tussock forming with smaller rhizomes and are reported to have superior abiotic stress tolerance [14,25]. The wild accessions of $M$. sacchariflorus are high yielding but were reported as less resilient [13].

\subsection{Experimental Setup}

Plants were grown in a glasshouse (Venlo), in a $14 \mathrm{~h}$ photoperiod using supplemental lighting in Aberystwyth, U.K. (52.4336 $\left.\mathrm{N}, 4.0173^{\circ} \mathrm{W}\right)$. The glasshouse was fitted with automatic vents and an extractor fan to help reduce variance attributable to environmental factors. Plants were grown in $5 \mathrm{~L}$ pots, with John Innes No. 2 compost, from approximately 20-30 g of rhizome cuttings.

Field or soil water-holding capacity defined as the amount of water held in the soil after the excess of gravitational water had drained' [33] was estimated from a pilot experiment. Pots were weighed daily for the 35 days of the experiment, to calculate water loss due to evapotranspiration, and the required amount of water added to maintain the desired water holding capacity of the soil. Target weight for each genotype was evaluated individually and was adjusted during the experiment to account for the biomass accumulation. Plants were grown under well-watered ( $85 \%$ field capacity) and moderate drought stress (15\% field capacity). All genotypes reached target weight set for the soil moisture deficit after $8 \pm 1$ days after the last irrigation.

\subsection{Determination of Traits}

On the last day of the experiment (75 days after potting), plants were harvested to determine fresh and dry biomass. Fresh material was dried at $60^{\circ} \mathrm{C}$ until constant weight was achieved at which point dry biomass was recorded. 


\subsubsection{Measurements of the Morphological Traits}

Growth measurements were made every 2-3 days over the course of 5 weeks. The length of the primary stem was measured, using a graduated ruler, from the soil surface to the ligule of the youngest fully expanded leaf. Leaf area was calculated from measurements of leaf length (from the ligule to the leaf tip) and width (midpoint between the leaf tip and the ligule) using the equation described by Clifton-Brown \& Lewandowski [34]: Area $\left(\mathrm{mm}^{2}\right)=0.74 \times$ length $(\mathrm{mm}) \times$ width $(\mathrm{mm})$.

Due to plant growth and new leaf development, leaf area was measured on a different but standard leaf throughout the experiment, the youngest leaf with a differentiated ligule, this method was previously shown to successfully detect the quantitative impact of drought stress on leaf area in $M . \times$ giganteus [26]. Additionally, the number of leaves (on the main stem) and stems were counted bi-weekly.

\subsubsection{Physiological Measurements}

All physiological measurements were taken between 8:00 $\mathrm{h}$ and 14:00 $\mathrm{h}$ to avoid significant potential diurnal variation in stomatal conductance $\left(g_{\mathrm{s}}\right)[35,36]$. Conductance of leaf surfaces was measured once a week using AP4 Leaf Porometer (Delta-T Devices) from the middle, avoiding the midrib, of the youngest fully expanded leaf with the ligule.

Net $\mathrm{CO}_{2}$ assimilation rate $\left(A_{\mathrm{N}}\right)$, stomatal conductance, and net transpiration rate $(E)$ were measured using a calibrated portable Infrared Gas Analyzer (IRGA) equipped with an integrated fluorometer (Walz GFS-3000, Heinz Walz, Germany). Measurements were recorded, three times throughout the experiment, on five plants per genotype per treatment at approximately 2-week intervals: before, and two and four weeks after treatment began.

\subsection{Data Analysis}

\subsubsection{Drought and Productivity-Related Indexes}

A selection of indexes was calculated to describe the plant performance and responses to stress. Water use efficiency defined as g of dry biomass produced per $\mathrm{kg}$ of water [37,38], was calculated by measuring total water applied during the experiment and above-ground dry biomass at the end of the experiment. Gravimetric data for pots without plants were used for all treatments to adjust for evaporative water loss.

Additionally, three indexes of phenotypic plasticity (IP) [39], plant productivity and resilience to water deficit [40] were calculated. Index of plasticity was calculated according to Equation (1) where trait $_{\max }$ is the trait average with highest values (control) and trait $_{\min }$ the trait average with lowest values (drought condition).

$$
I P=\left(\text { trait }_{\text {max }}-\text { trait }_{\text {min }}\right) \text { trait }_{\text {max }}{ }^{-1}
$$

Yield stress score index (YSSI) was calculated according to Equation (2) and combined the stress susceptibility index (SSI) [41], and stress tolerance index (STI) defined by Fernandez [42] (Table S2).

$$
Y S S I=0.5(S T I+S S I)
$$

Yield potential score index (YPSI) summarised mean productivity index (MP) [43], stress tolerance index (STI), stress susceptibility index (SSI), and tolerance index (TOL) [44] (Table S2), and is shown in Equation (3).

$$
Y P S I=0.5(M P+S T I)-0.5(S S I+T O L)
$$

\subsubsection{Growth Curves Analysis}

Growth and elongation data were summarised using non-parametric characteristics of curves. The main stem length and leaf area for each plant were interpolated using a univariate penalized cubic 
regression spline using the R package (mgcv) [45] based on the method by Hurtado et al. [46] and adjusted to study plant growth as described by Malinowska et al. [30]. The period of analysis was six weeks, starting 32 days after the potting, one week before the drought stress was applied. The fitting process resulted in smooth curves for leaf and stem growth for every plant analyzed. The features of the fitted curves were obtained using the first derivative calculated from the smoothed curves. Mean progression rate (mprate), as defined by Hurtado et al. [46], indicated the average rate of change of the growth curve throughout the experiment and was the mean of the first derivative calculated for each 2-3 days interval. The mprate reflected the speed of growth or the change in size across the experiment.

\subsubsection{Statistical and Graphical Analyses}

Data were analyzed using Statistical Software in R version 3.2.1 [47]. Statistical significance (when appropriate) was indicated as follows: $p \leq 0.1,{ }^{*} p \leq 0.05 ;{ }^{* *} p \leq 0.01$; ${ }^{* * *} p \leq 0.001$. Regression models were built to test which phenotypic and physiological traits contributed to variation in the dry biomass of the plants at the end of the experiment. The analysis was performed separately for the subset of plants under control and drought treatments to eliminate the substantial treatment effect at the population level. Traits that were tested included: main stem length, number of stems, number of leaves on the main stem, leaf length, leaf width, leaf area, maximal and average growth rate of stems and accumulation of leaf area, and area under the curve for stem growth, leaf area, and stomatal conductance. General linear models were obtained using automated model selection and dredge function from the MuMIn package [48] and the best model selected based on the Aikake information criterion value and delta $<6$ [49]. All time course, longitudinal studies were analyzed with linear mixed-effects models using the lme4 [50] package. The overall time course of various measurements was modelled with an orthogonal polynomial and fixed effect of treatment (control vs. drought; within genotypes) on all time terms. The models also included the individual plant random effect on all time terms. $p$-values and the best models were obtained by likelihood-ratio test [51] for the general effect and interactions against the null model (without the effect). Outliers, which exceeded 2.5 standard deviations, were removed. For the single time point analyses (e.g., biomass, WUE, and other end-of-experiment measurements) single stratum analysis of variance was performed using built-in R functions.

\section{Results}

\subsection{Biomass Accumulation}

Dry biomass varied 45-84 $\mathrm{g}$ for summed leaves and stems and 38-61 $\mathrm{g}$ for roots and rhizomes. WAT03 and WAT09 accumulated the highest dry biomass above- and below-ground under both treatments (Figure 1). Under well-watered conditions, there was significant variation in above-ground biomass accumulation between genotypes, whilst under moderate drought biomass accumulations were relatively similar. Drought had the most severe effect on WAT03 with a decrease of leaf and stem biomass of up to $35 \%$ in comparison to control plants. When compared to control plants leaf biomass of WAT04 was significantly lower under drought stress (Table 1). Drought stress significantly lowered leaf and stem yield (30-35\%) of M. $\times$ giganteus but not dry biomass of roots and rhizome. Biomass of WAT10 and WAT11 genotypes was not significantly affected by drought stress. 

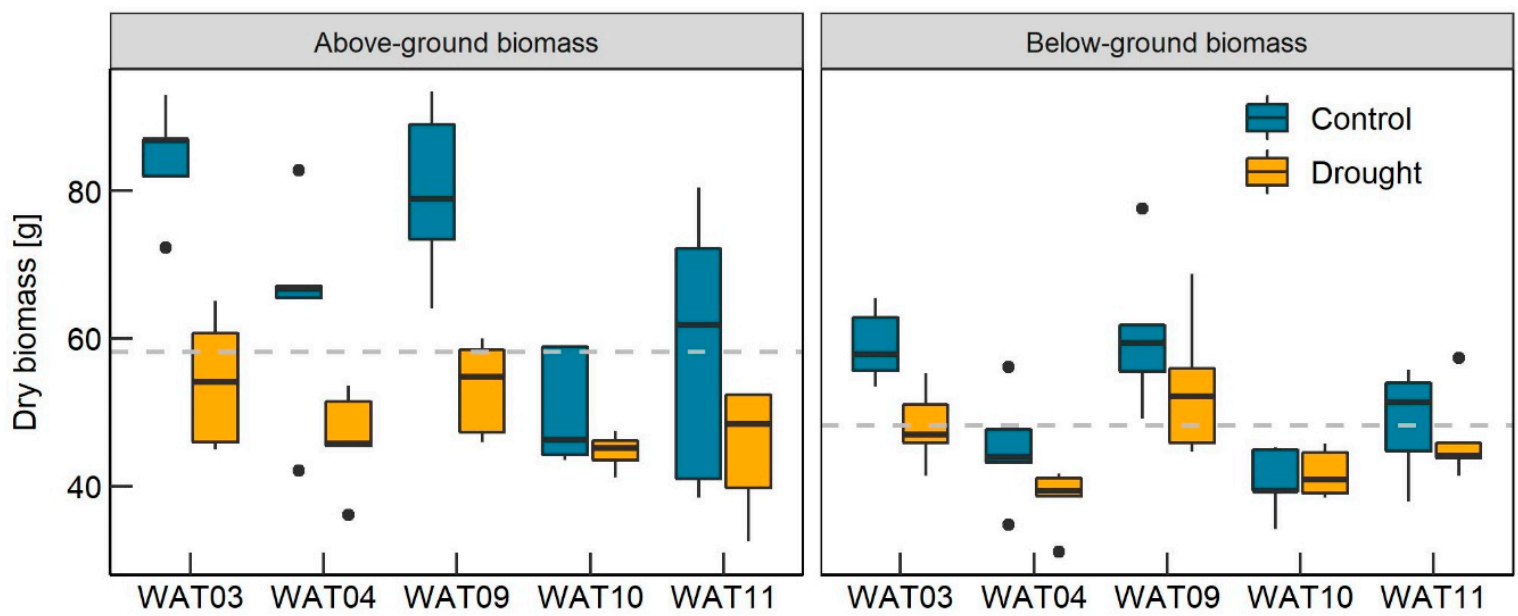

Figure 1. Boxplot of above and below-ground dry matter under control and drought stress treatments $(n=5)$. Horizontal, dashed, line is showing the populations average; outliers (which exceeded 2.5 standard deviations) are plotted as individual points.

Table 1. Effect of drought stress treatment on biomass accumulation, above and below-ground, separated into leaves, stems, rhizomes, and roots, compared to control; $p$-value indicates the statistical significance for a given term within the model. Significance of differences are shown as $p \leq 0.05$; ** $p \leq 0.01 ;{ }^{* * *} p \leq 0.001 ; \mathrm{ns}=$ not significant.

\begin{tabular}{cccccc}
\hline & Rhizome (g) & Root (g) & Stem (g) & Leaf (g) & Total Biomass (g) \\
\hline WAT03 & $* *$ & $*$ & $* * *$ & $* * *$ & $* * *$ \\
WAT04 & $\mathrm{ns}$ & $\mathrm{ns}$ & $\mathrm{ns}$ & $*$ & $\mathrm{~ns}$ \\
WAT09 & $\mathrm{ns}$ & $\mathrm{ns}$ & $* *$ & $* *$ & $*$ \\
WAT10 & $\mathrm{ns}$ & $\mathrm{ns}$ & $\mathrm{ns}$ & $\mathrm{ns}$ & $\mathrm{ns}$ \\
WAT11 & $\mathrm{ns}$ & $\mathrm{ns}$ & $\mathrm{ns}$ & $\mathrm{ns}$ & $\mathrm{ns}$ \\
\hline
\end{tabular}

\subsection{Miscanthus Morphology}

\subsubsection{Length of the Main Stem}

Stem elongation curves were highly variable $(p<0.001)$ between genotypes. The main stem of WAT09 was significantly longer than the other four genotypes. In WAT04 stem elongation declined rapidly, in comparison to control plants, after seven days of drought treatment $(p<0.01)$. After 22 days a moderate response to drought treatment resulted in stem length under drought being significantly lower in WAT09 than in control plants. WAT11 plants showed no significant impact on the main stem length under drought stress (Figure 2A). 

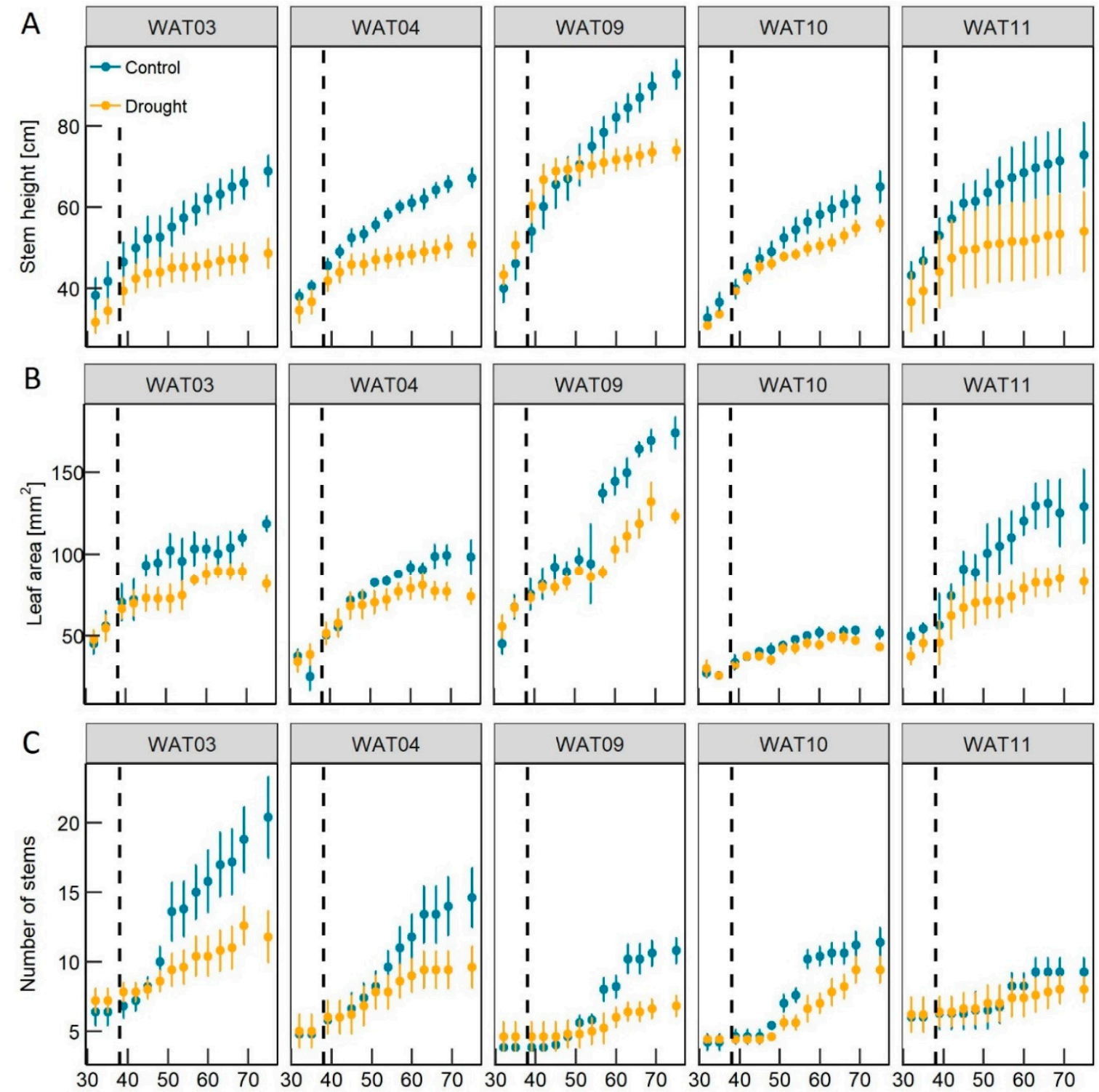

\section{Days from planting}

Figure 2. Above-ground morphology characteristics. The main stem elongation (A), youngest fully expanded leaf area development (B), and increase in stem number $(\mathbf{C})$ curves for control and drought treatments of five genotypes. The dashed vertical line indicates the onset of drought stress. Values represent means $\pm \operatorname{SEM}(n=5)$; SEM-standard error of the mean.

\subsubsection{Leaf Area}

At the population level, drought stress negatively affected the area of newly formed leaves $(p<0.05)$. The area of the youngest fully expanded leaves in WAT03 plants was significantly lower in drought-stressed than control treated plants after only seven days $(p<0.1)$. Leaf area was small and very similar between treatments in WAT10, but differences were observed 37 days after the start of drought stress. The leaf areas of the other three genotypes diverged between the treatments between 22 and 28 days after the drought was applied (Figure 2B). By the end of the experiment leaf area of WAT09 was significantly larger $(p<0.001)$ than the other four genotypes under both treatments (Figure 2B). 


\subsubsection{Number of Stems}

WAT3 and WAT4 produced the most stems, whilst, in other genotypes stem numbers were comparable. Under moderate drought stress, stem number was lower in all genotypes except for WAT11 which was not significantly affected by treatment. A significant reduction in stem number was observed for WAT10 at 16 days of the treatment $(p<0.01)$. Stem number in WAT03, WAT09 and WAT04 was reduced in response to drought after between 25 and 31 days (Figure 2C).

\subsubsection{Growth Curves Analysis}

The mprate identified differences between slow and fast growing plants. Variation in mprate could be explained by both treatment and genotype. Changes in leaf and stem growth and final sizes differed among genotypes in response to drought. Drought stress resulted in a lower stem mprate for all genotypes. WAT09 plants showed a considerably higher mprate for stem elongation and leaf expansion when compared to plants of other genotypes (Figure 3). Leaf area and leaf mprate were the lowest in WAT10 plants, with drought having the smallest effect on leaf expansion in this genotype (Table 2).
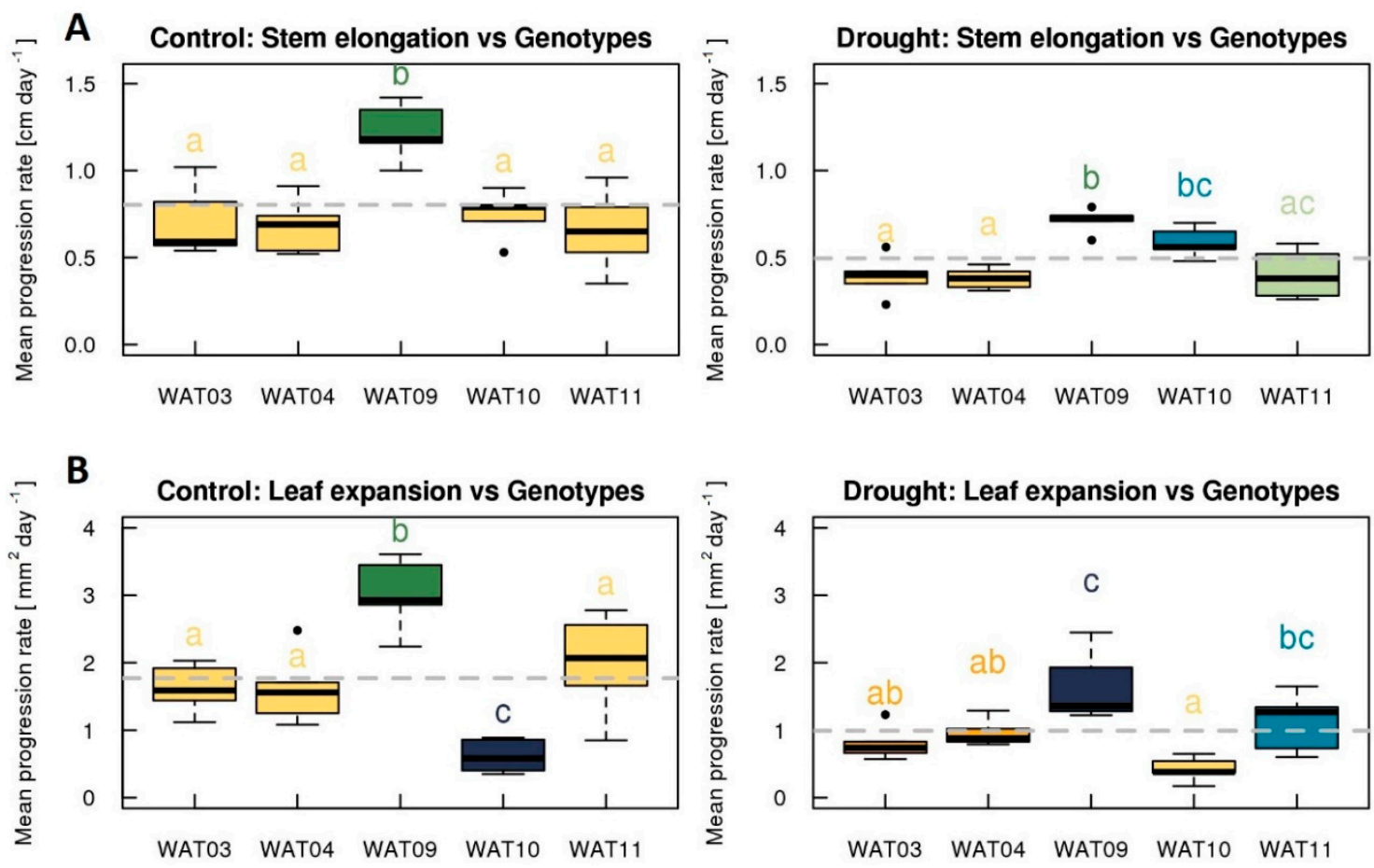

Figure 3. Mean stem elongation rate (A) and leaf expansion rate (B) of five miscanthus genotypes with varying dry biomass under control (left) and drought stress (right) treatments; significant differences between genotypes are based on Tukey multiple comparison test and denoted by lettering above the boxes (conf. level = 0.95); each statistical group is drawn with the same colour; grey horizontal, dashed, line is showing the populations average; outliers (which exceeded 2.5 standard deviations) are plotted as individual points.

The final morphology and curve characteristics of morphological traits were assessed by PCA. Under each treatment, WAT10 was grouping with two M. sinensis types (WAT03 and WAT04) while WAT09 and WAT11 were clustering together (Figure S1). 
Table 2. Analysis of variance on effects of applied treatment on growth curve characteristics and phenotypic traits at harvest of drought-stressed miscanthus genotypes compared to controls; mprate-the mean progression rate of the growth curve; SE-measure of the uncertainty in the coefficient; $p$-value indicates the statistical significance for a given term within the model. Significance of differences are shown as $p \leq 0.1{ }^{*} p \leq 0.05 ;{ }^{* *} p \leq 0.01 ;{ }^{* * *} p \leq 0.001$; ns = not significant.

\begin{tabular}{|c|c|c|c|c|}
\hline \multicolumn{5}{|c|}{ The length of the Main Stem $(\mathrm{cm})$} \\
\hline & \multicolumn{2}{|c|}{ Mprate $\left(\mathrm{cm} \mathrm{d}^{-1}\right)$} & \multicolumn{2}{|c|}{ Stem Length at Harvest $(\mathrm{cm})$} \\
\hline & Coefficient \pm SE & $p$ & Coefficient \pm SE & $p$ \\
\hline WAT03 & $-0.32 \pm 0.11$ & * & $-20.40 \pm 5.29$ & ** \\
\hline WAT04 & $-0.30 \pm 0.08$ & $* *$ & $-16.80 \pm 3.81$ & $* *$ \\
\hline WAT09 & $-0.51 \pm 0.08$ & $* * *$ & $-18.60 \pm 4.32$ & $* *$ \\
\hline WAT10 & $-0.16 \pm 0.07$ & * & $-9.60 \pm 4.51$ & . \\
\hline WAT11 & $-0.26 \pm 0.12$ & . & $-12.80 \pm 13.24$ & ns \\
\hline \multicolumn{5}{|c|}{ Leaf Area $\left(\mathrm{mm}^{2}\right)$} \\
\hline & \multicolumn{2}{|c|}{ Mprate $\left(\mathrm{mm} \mathrm{d}^{-1}\right)$} & \multicolumn{2}{|c|}{ Leaf Area at Harvest $\left(\mathrm{mm}^{2}\right)$} \\
\hline & Coefficient \pm SE & $p$ & Coefficient $\pm \mathrm{SE}$ & $p$ \\
\hline WAT03 & $-0.82 \pm 0.20$ & $* *$ & $-36.52 \pm 6.81$ & $* * *$ \\
\hline WAT04 & $-0.66 \pm 0.26$ & * & $-24.36 \pm 11.12$ & . \\
\hline WAT09 & $-1.37 \pm 0.34$ & $* *$ & $-50.80 \pm 10.26$ & $* *$ \\
\hline WAT10 & $-0.20 \pm 0.14$ & ns & $-8.52 \pm 4.39$ & . \\
\hline WAT11 & $-0.86 \pm 0.39$ & . & $-36.34 \pm 21.28$ & ns \\
\hline
\end{tabular}

\subsection{Physiological Traits}

\subsubsection{Stomatal Conductance}

At the whole population level, there was a significant effect of drought stress on $g_{\mathrm{s}}(p<0.001)$. WAT09 plants exhibited the highest values of $g_{\mathrm{s}}$ and stomata responded most rapidly to drought in this genotype (Figure 4 ) with a significant decline in $g_{\mathrm{s}}$ after ten days $(p<0.001)$. Stomatal conductance significantly decreased in the two $M$. sacchariflorus genotypes after 13 days of drought $(p<0.01)$. In WAT10 and WAT11 plants, a significant reduction in stomatal conductance occurred a week later $(p<0.05)$.
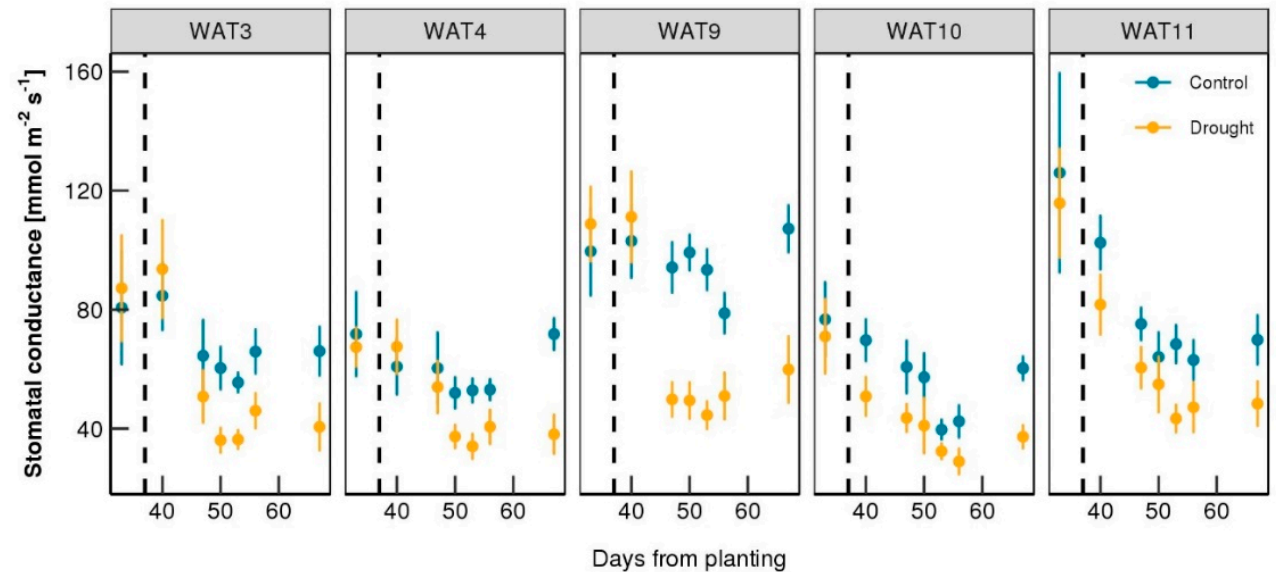

Figure 4. Stomatal conductance $\left(g_{\mathrm{s}}\right)$. The change in stomatal conductance of 5 miscanthus genotypes growing for 75 days, drought stress was applied to half the plants at day 37 indicated by the vertical dashed line. Values represent means \pm SEM $(n=5)$; SEM—standard error of the mean.

\subsubsection{Photosynthetic Gas Exchange}

Net photosynthesis $\left(A_{\mathrm{N}}\right)$ of WAT09 was significantly higher than for plants of other genotypes $(p<0.001)$ except for WAT04, which exhibited an almost identical pattern of net $\mathrm{CO}_{2}$ 
assimilation rates. The values of $E$, as well as $A_{\mathrm{N}}$ in well-watered plants, were lowest in WAT11 $\left(1.2 \pm 0.06 \mathrm{mmol} \mathrm{H}_{2} \mathrm{O} \mathrm{m}^{-1} \mathrm{~s}^{-1}\right.$ and $12.54 \pm 1.24 \mu \mathrm{mol} \mathrm{m} \mathrm{m}^{-2} \mathrm{~s}^{-1}$ respectively) and highest in WAT09 $\left(2.1 \pm 0.1 \mathrm{mmol} \mathrm{H}_{2} \mathrm{O} \mathrm{m}^{-1} \mathrm{~s}^{-1}\right.$ and $\left.24.04 \pm 0.68 \mu \mathrm{mol} \mathrm{m}^{-2} \mathrm{~s}^{-1}\right)$. Drought stress significantly affected $A_{\mathrm{N}}$ and $E$ of three genotypes WAT04, WAT09, and WAT11 (Table S3). The applied drought stress was insufficient to affect $A_{\mathrm{N}}$ or $E$ of WAT03 and WAT10 at any time point (Table S3).

\subsection{Water Use Efficiency}

The average shoot WUE in well-watered plants varied from as low as $6.7-10.1 \mathrm{~g} \mathrm{~kg}^{-1}$ in WAT10 and WAT04 plants, and under drought stress varied from as high as $12.6-17.3 \mathrm{~g} \mathrm{~kg}^{-1}$ in WAT03 and WAT11, respectively (Table S4). The drought treatment resulted in a statistically significant increase of WUE for all five genotypes (Table S4). WUE more than doubled in $M$. sinensis plants grown under drought stress compared to controls. WAT03 and WAT09 plants exhibited the smallest changes in WUE between treatments, whilst WAT04 plants exhibited an intermediate response.

\subsection{Drought and Productivity-Related Indexes}

Phenotypic plasticity describes the dynamic change in morphology or physiology of a single genotype (or at the population level) in response to the environment [52,53]. The index of phenotypic plasticity (Figure 5) revealed that below-ground dry biomass was the least responsive (plasticity) trait. Response to drought stress in WAT10 and WAT11 could be most readily observed through the changes in stomatal conductance and area of the youngest fully expanded leaf. For WAT09 and the $M$. sacchariflorus genotypes above-ground dry biomass was the most plastic trait, followed by the length of the main stem. WAT09 and WAT03, exhibited the greatest summed plasticity, whilst WAT10 with the most fixed traits, was at the opposite end of the gradient (Figure 5).

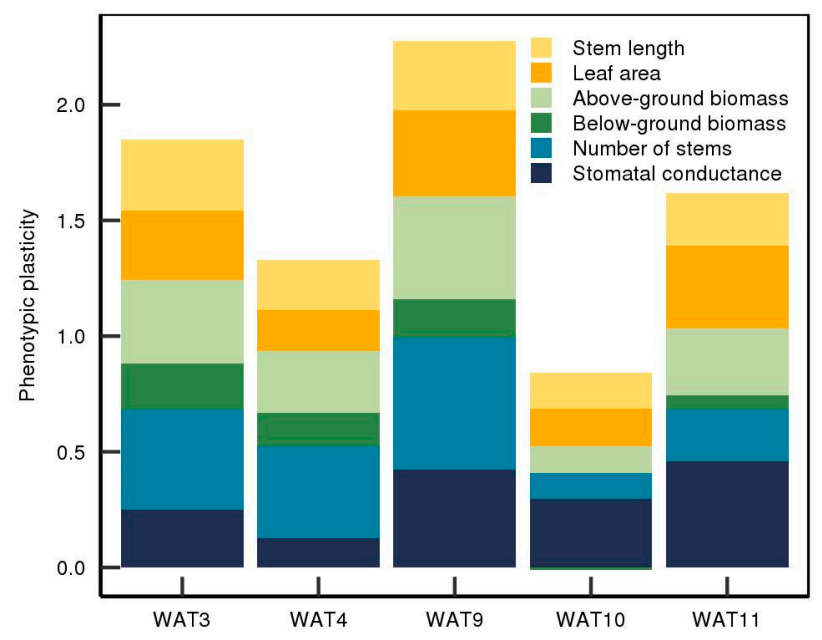

Figure 5. Index of phenotypic plasticity for six phenotypic traits for five genotypes: the length of the main stem, youngest fully expanded leaf area, above-ground biomass, and below-ground dry biomass at the end of the experiment, number of stems, and stomatal conductance.

Yield, stress and potential, score indexes that summarised drought tolerance, susceptibility, and productivity were plotted against above-ground dry biomass under control (Figure 6A) and drought (Figure 6B) conditions. Plants of WAT03 and WAT09, which exhibited the highest YSSI also exhibited the highest biomass accumulation under both drought and control treatments. Plants of WAT10, which exhibited lower yield and YSSI, also exhibited the highest YPSI of all genotypes. YSSI correlated well with the yield under drought, while YPSI favoured genotypes with the lowest yield penalty but not necessarily the highest biomass accumulation. 

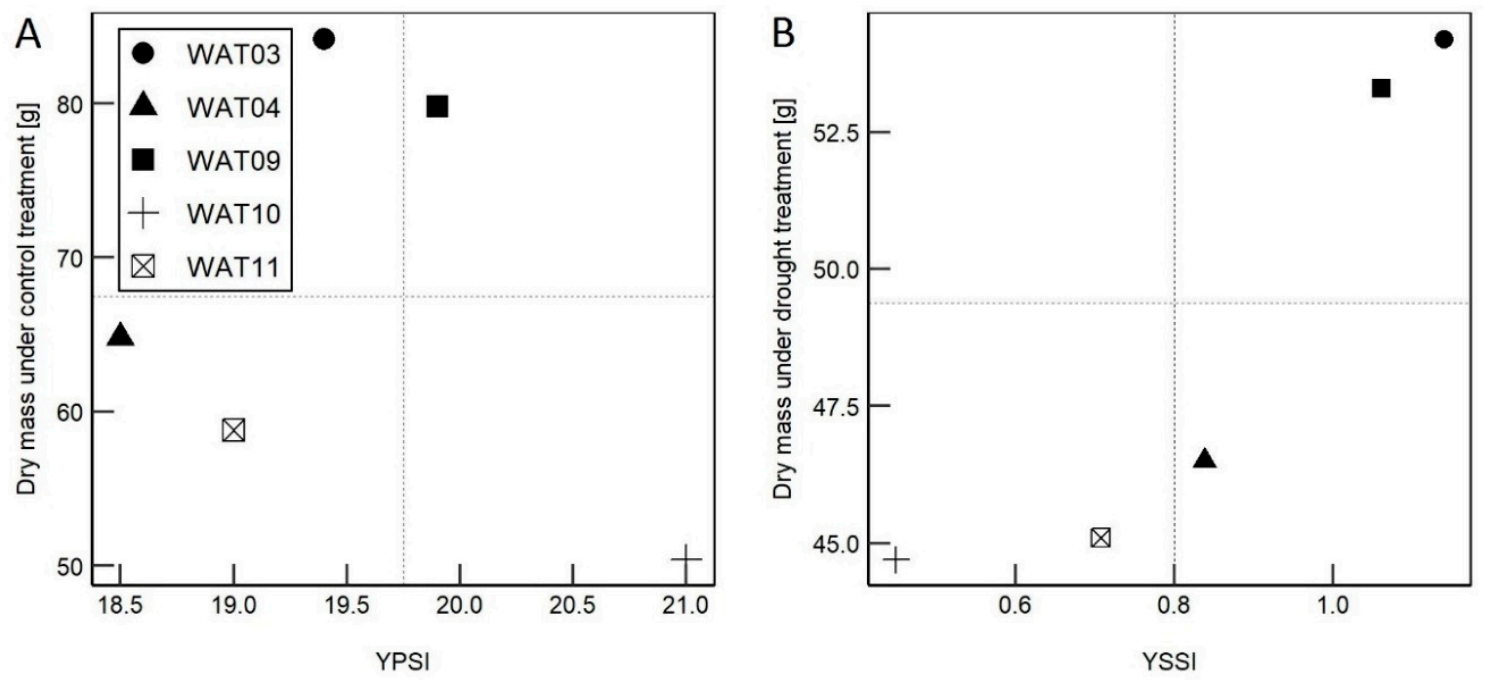

Figure 6. The values of the yield potential score index (YPSI) versus above-ground biomass under control conditions (A), and the yield score stress index (YSSI) versus above-ground dry biomass under drought stress (B) for each genotype.

\subsection{Linear Regression Models}

The variation in the above-ground dry biomass of the control plants was explained by the length of the main stem and the number of stems with $\sim 85 \%$ variation explained by the model (Table 3 ). The dry biomass of the aerial parts of the plants under drought was explained by the length of the main stem, the number of stems, as well as the youngest leaf area $(p<0.01)$ and area under the stomatal conductance curve, with $\sim 70 \%$ of variation explained by the model. In comparison to the control plants, the dry biomass of the plants under drought was explained by a higher number of variables, and less variation was described (Table 3). Additionally, the effect of stem length on the dry biomass was less significant under drought than under control conditions, while the number of stems as a measure was highly significant under both treatments. The variation in dry biomass within the population under moderate drought decreased compared to variation under control conditions.

Table 3. The variables explaining the above-ground biomass accumulation under well-watered and drought conditions in the tested population; SE-measure of the uncertainty in the Coefficient; $t$ value is derived from the $t$-statistic and $p$-value indicates the statistical significance for a given term within the model. Significance of differences are shown as $p \leq 0.1{ }^{*} p \leq 0.05 ;{ }^{* *} p \leq 0.01 ;{ }^{* *} p \leq 0.001$.

\begin{tabular}{cccc}
\hline & Coefficient \pm SE & $t$-Val & $p$ \\
\hline Intercept & Control & & \\
Stem length & $-36.19 \pm 10.36$ & -3.49 & $* *$ \\
Number of stems & $1.06 \pm 0.12$ & 8.68 & $* * *$ \\
& $2.06 \pm 0.32$ & 6.52 & $* * *$ \\
\hline Intercept & Drought Treatment & & $*$ \\
Stem length & $12.67 \pm 5.78$ & 2.19 & $*$ \\
Number of stems & $0.20 \pm 0.09$ & 2.17 & $*$ \\
Leaf area & $0.47 \pm 0.09$ & 4.96 & $*$ \\
Stomatal conductance curve & $0.65 \pm 0.09$ & 2.83 & $*$ \\
\hline
\end{tabular}

\section{Discussion}

A broad range of traits associated with biomass accumulation were compared across five miscanthus genotypes under well-watered and drought treatments. The comparison included the industry-standard M. $\times$ giganteus (WAT09), so results would be transferable to commercial 
production $[13,15,22]$. It was demonstrated that despite a rapid decline in yield under drought, the superior ideotype was high yielding under well-watered conditions and plastic under drought. We conclude, based on the genotypes studied, that resilience per se is unlikely to produce a superior yield in an environment with changing water availability because of the associated yield penalty in the absence of stress.

The genotypes studied included two broadly different morphotypes so that the impact of contrasting traits could be assessed. All genotypes grown in our study reached the target weight at approximately the same time ( \pm 1 day), so uniform water limitation within the population could be assumed. A moderate soil moisture deficit was chosen (15\% FC) to generate physiologically relevant responses to biomass accumulation under stress, i.e., we were focused on traits involved in sustaining growth not escape from terminal drought. In three genotypes (WAT03, WAT04 and WAT09), the applied moderate drought treatment resulted in a reduction in dry matter, compared with cloned plants growing in control treatments. Growth inhibition by drought may result from turgor loss, stomatal closure and molecular rearrangements which lead to disturbance in photosynthesis, nutrient and carbohydrate metabolism, or ion uptake [54-56]. A broad range of these traits was assessed, and it was demonstrated that the five genotypes responded differently to the application of moderate drought treatment.

\subsection{High Yielding Miscanthus Genotypes Demonstrated a Diversity of Responses to Drought}

Plants of WAT09 produced the highest above-ground biomass and were characterized as having long stems, large standard leaf area and high stem and leaf growth rates. WAT03 and WAT04 accumulated intermediate levels of above-ground biomass in the well-watered treatment. WAT10 accumulated lower amounts of above-ground biomass, showed the smallest area of the uppermost leaf with a ligule and the lowest leaf growth rate when compared with other genotypes. WAT11 accumulated lower amounts of above-ground biomass and produced a low number of stems, but was characterised by leaf area and growth rates.

Not all genotypes showed gross differences in morphological traits between the two treatments. However, for all plants trajectories of stem growth, leaf expansion, and tillering (stem number) curves were significantly affected by the applied treatment. Several studies, both in greenhouse and field conditions, reported that stem elongation and leaf area were significantly affected in M. $\times$ giganteus and M. sacchariflorus but not in M. sinensis $[17,25-27,29,34,57]$. In the present study, the morphological trait changes under applied drought conditions were in line with previous findings for pots experiments $[25,28,29,34,58]$.

Yield reduction is the most important effect of limited water availability on biomass crops. Multiple studies, conducted in the field, and glasshouse, are showing the adverse effect of the poor water supply on the miscanthus biomass accumulation $[11,26,28,29,34,58]$. In the present study, applied treatment resulted in a reduction in dry matter only in $M . \times$ giganteus and $M$. sacchariflorus. The decrease in dry matter was mostly due to lowered leaf weight, with very little to no change in below-ground biomass.

The correlation between above and below-ground biomass declined under drought from an adjusted $R^{2}$ of 0.80 for well-watered plants to 0.44 (data not shown) for drought treated plants, indicating the simple relationship between above- and below-ground biomass in control plants was more complex under drought stress. In our study, except for WAT11, plants responded to drought by increasing the flux of biomass underground. Increased below-ground biomass may reflect increased scavenging for water or an escape from drought to vegetative rhizome production. However, such strategy may not necessarily be beneficial for the final yield, as according to Poorter et al. [59] under mild to moderate drought stress changes in biomass allocation may results in suboptimal growth after re-watering.

In contrast to some previous studies [25] and in agreement with others [26] we showed the commercial type $M . \times$ giganteus (WAT09) had high water use, low water use efficiency and high stomatal conductance in control treatments but that stomata were responsive to drought. Considering stomatal responses and growth kinetics, we would classify WAT09 as an optimistic plant that grows as 
if water will be forever plentiful. This is similar to the accessions from North Taiwan discussed by Weng [24]; "optimistic" accessions from the north, where summer rainfall was plentiful, had higher photosynthetic rates even under drought compared to accessions from the south where seasonal drought was common.

\subsection{Changes in Photophysiology Occurred Late and Did Not Have a Significant Impact on Biomass Accumulation}

The predicted consequence of lowered stomatal conductance, and therefore limited $\mathrm{CO}_{2}$ diffusion and decreased transpiration, would be impaired photosynthesis [60]. In our study, even though all genotypes exhibited a reduction in stomatal conductance, a significant decrease in $A_{\mathrm{N}}$ was restricted to three genotypes. In maize and miscanthus under moderate drought stress, only minor fluctuations in net carbon assimilation have previously been reported $[25,29,61]$. Changes to $A_{N}$ in drought-stressed plants depend not only on stomatal closure but also on metabolic limitation [62-64].

Even though stomatal conductance was lower under drought stress in all genotypes, and net carbon assimilation rate was lower in three genotypes, only $M$. sacchariflorus and $M . \times$ giganteus exhibited significant morphological responses to drought. The assimilation rate of $M$. sacchariflorus genotype, WAT03, was not affected, even though biomass accumulation and growth rate were significantly decreased under drought. For all genotypes, the reduction of stomatal aperture did not change linearly and nor were stomata completely closed. Despite fluctuations in the $g_{\mathrm{s}}$ values, once conductance was significantly decreased, it maintained a similar level, which may indicate the acclimation to new homeostasis under lower water availability. Thus, growth alteration under moderate stress is not the consequence of reduced photosynthetic rate and resource limitation but an adaptive response [55,65-67].

\subsection{High Tolerance to Drought Was Associated with Low Plasticity in Phenotypic Traits and Low Overall Biomass Accumulation}

Independent of final yield, drought stress resulted in a decrease in main stem length, leaf area, and stem number to differing extents in all genotypes. However, within the time frame of the experiment, all plants exposed to moderate drought were able to maintain some level of growth. $M . \times$ giganteus was most sensitive to drought and exhibited the highest values of phenotypic plasticity for most of the analyzed morphological and physiological traits. With the most fixed traits, WAT10 was the most drought-tolerant genotype. Morphological traits in WAT10 were moderately impacted by drought stress, yield penalty was insignificant, and it was considerably smaller than the other genotypes under control conditions. This was in agreement with the study of Clifton-Brown and Lewandowski [34] in which moderate drought reduced yield, relative to controls, of $M$. sacchariflorus and $M . \times$ giganteus but not $M$. sinensis. However, even with low yield accumulation and low phenotypic plasticity WAT10 exhibited relatively high mean stem elongation rate (under both treatments), and a rapid decrease of stomatal conductance under drought stress. The plasticity rankings indicated that the two genotypes (WAT03 and WAT09) most responsive to drought also had the highest yield under optimal conditions, while the least plastic and most tolerant genotype produced the smallest yield. In analyzed genotypes, drought tolerance was associated with reduced phenotypic plasticity and a water-conserving strategy. While conservative use of water may promote drought-resilience, under favourable conditions when resources are abundant, the benefit of plant survival may be out-weighed by the inferior growth performance and meagre biomass gain [68-70]. Therefore if a low level of plasticity is associated with a high level of drought tolerance but low biomass accumulation, it is unlikely that selecting for fixed traits will maximize biomass accumulation throughout a long growing season.

Biomass values were plotted against yield score stress index and yield potential score index, proposed by Thiry et al. [40] and captured two major characteristics. The results confirmed the conclusions above. Under a given stress level, WAT10 was most tolerant but accumulated the lowest quantities of biomass while WAT03 and WAT09 were high performing genotypes despite the high yield penalty. This suggests that high resilience will not necessarily result in the best performance integrated 
across a long season, including periods of varying water availability. Plants, with conserved water use, could be the right choice for arid regions but would not produce suitable amounts of biomass under temperate climates [71,72].

Drought indexes indicated a significant drought-related decline in biomass accumulation. However, absolute differences in biomass between genotypes decreased under soil moisture deficit, suggesting there was no intrinsic penalty associated with high biomass in well-watered genotypes giving rise to low biomass under drought. $M$. sacchariflorus species, such as WAT03, were identified as good candidates for maintaining biomass accumulation under drought similar to that of $M . \times$ giganteus. The production of higher amounts of biomass; however, required more water. Genotypes WAT03 and WAT09, in particular, used more water under both treatments, which under field conditions may deplete soil water and exacerbate drought stress or have an adverse effect on local soil hydrology [73].

\subsection{A More Complex Linear Model Was Required to Explain the Yield from Drought-Stressed Miscanthus}

Stem and leaf measurements over time were used to produce a functional description of any changes occurring. We used these functional traits along with accumulated biomass, morphological and photophysiological traits that had been associated with responses to drought stress in plants $[25,55,74-76]$ to identify the most parsimonious model for biomass accumulation under both conditions. Yield under well-watered treatment was best explained by stem traits, following the previous studies which identified these traits as major correlates with biomass accumulation in miscanthus in the field and controlled environment conditions [22,77]. However, a more complex model was required to explain variation in the biomass accumulation under drought stress, and this model explained less of the variation, i.e., we did not add more variables to explain more variance. Stem length and stem number remained in the model but explained less of the variation and the most parsimonious model included leaf area and stomatal conductance, suggesting that selection for biomass accumulation resilience, i.e., superior yield across a range of water availabilities in miscanthus should include these additional traits.

\section{Conclusions}

The effect of drought stress at the physiological level was evident for all five genotypes and different morphotypes and allowed us to examine different combinations of responses to drought. Stomatal conductance was reduced in response to water deficit. However, assimilation capacity was not significantly affected; plants did not senesce, reduced physiological activity and wilting were limited. The lower final yield of $M$. sinensis morphotypes under both conditions was mainly due to the low mean leaf development rate, small plant leaf area (WAT10) and very few stems (WAT11). Genotypic diversity in accumulated biomass yield declined under drought stress, but sufficient variation was present across a broad range of traits studied to test associations with yield. The traits that most contributed to the accumulation of higher biomass in optimal and in droughted conditions were stem number and canopy height. Selection for superior performance per se under more optimal conditions appears to be a viable strategy and perhaps a most practical one given the incredible diversity of severity and duration of drought stress possible in the natural environment. Therefore given the importance of yield and the small number of additional traits identified, a selection strategy such as Genotype by Yield $\times$ Trait would seem most appropriate, focusing on improving stem and leaf growth and stomatal traits in combination with yield.

Supplementary Materials: The following are available online at http://www.mdpi.com/2073-4395/10/8/1194/s1, Table S1: Core genotypes used in the experiment with information on species, country of origin and ploidy; Table S2: Drought indices; Figure S1: Principal component analysis (PCA) of morphology and biomass characteristics measured at harvests, of control (A) and plants under moderate drought stress (B); Table S3: Analysis of variance on effects of drought stress treatment on the net transpiration rate, and net $\mathrm{CO}_{2}$ assimilation of miscanthus genotypes; Table S4: The mean values of water use efficiency and cumulative water use for each genotype under both treatments and the analysis of variance on the effect of drought stress on shoot water use efficiency (WUE), and the absolute water use compared to control. 
Author Contributions: Conceptualization, P.R. and I.D.; Methodology, M.M., P.R., and I.D.; Investigation, M.M.; Resources, P.R.; Writing—original draft preparation, M.M.; Writing—review and editing, P.R. and I.D.; Supervision, P.R.; Funding acquisition, P.R. and I.D. All authors have read and agree to the published version of the manuscript.

Funding: Work reported in this manuscript was funded by the Biotechnology and Biological Sciences Research Council (BBSRC) (Grant numbers BBS/E/W/10963A01 and BBS/E/W/0012843A) and the EU FP7 project WATBIO (Development of improved perennial non-food biomass and bioproduct crops for water stressed environments-No. 311929).

Conflicts of Interest: The authors declare no conflict of interest.

\section{References}

1. Kluts, I.; Wicke, B.; Leemans, R.; Faaij, A. Sustainability constraints in determining European bioenergy potential: A review of existing studies and steps forward. Renew. Sustain. Energy Rev. 2017, 69, 719-734. [CrossRef]

2. McCalmont, J.P.; Hastings, A.; McNamara, N.P.; Richter, G.M.; Robson, P.R.H.; Donnison, I.; Clifton-Brown, J. Environmental costs and benefits of growing Miscanthus for bioenergy in the UK. GCB Bioenergy 2015, 9, 489-507. [CrossRef] [PubMed]

3. Shortall, O. "Marginal land” for energy crops: Exploring definitions and embedded assumptions. Energy Policy 2013, 62, 19-27. [CrossRef]

4. Jones, M.B.; Finnan, J.; Hodkinson, T.R. Morphological and physiological traits for higher biomass production in perennial rhizomatous grasses grown on marginal land. GCB Bioenergy 2014, 7, 375-385. [CrossRef]

5. Donnison, I.; Fraser, M. Diversification and use of bioenergy to maintain future grasslands. Food Energy Secur. 2016, 5, 67-75. [CrossRef]

6. Cattivelli, L.; Rizza, F.; Badeck, F.; Mazzucotelli, E.; Mastrangelo, A.M.; Francia, E.; Marè, C.; Tondelli, A.; Stanca, A.M. Drought tolerance improvement in crop plants: An integrated view from breeding to genomics. Field Crop. Res. 2008, 105, 1-14. [CrossRef]

7. Tuck, G.; Glendining, M.J.; Smith, P.; House, J.I.; Wattenbach, M. The potential distribution of bioenergy crops in Europe under present and future climate. Biomass Bioenergy 2006, 30, 183-197. [CrossRef]

8. Hastings, A.; Clifton-Brown, J.; Wattenbach, M.; Stampfl, P.; Mitchell, C.P.; Smith, P. Potential of Miscanthus grasses to provide energy and hence reduce greenhouse gas emissions. Agron. Sustain. Dev. 2008, 28, 465-472. [CrossRef]

9. Richter, G.M.; Riche, A.B.; Dailey, A.G.; Gezan, S.A.; Powlson, D.S. Is UK biofuel supply fromMiscanthuswater-limited? Soil Use Manag. 2008, 24, 235-245. [CrossRef]

10. Skirycz, A.; Vandenbroucke, K.; Clauw, P.; Maleux, K.; De Meyer, B.; Dhondt, S.; Pucci, A.; Gonzalez, N.; Hoeberichts, F.; Tognetti, V.B.; et al. Survival and growth of Arabidopsis plants given limited water are not equal. Nat. Biotechnol. 2011, 29, 212-214. [CrossRef]

11. Heaton, E.A.; Clifton-Brown, J.; Voigt, T.B.; Jones, M.B.; Long, S.P. Miscanthus for Renewable Energy Generation: European Union Experience and Projections for Illinois. Mitig. Adapt. Strat. Glob. Chang. 2004, 9, 433-451. [CrossRef]

12. Christian, D.G.; Riche, A.B.; Yates, N.E. Growth, yield and mineral content of Miscanthus $\times$ giganteus grown as a biofuel for 14 successive harvests. Ind. Crops Prod. 2008, 28, 320-327. [CrossRef]

13. Kalinina, O.; Nunn, C.; Sanderson, R.; Hastings, A.F.S.; Van Der Weijde, T.; Özgüven, M.; Tarakanov, I.; Schüle, H.; Trindade, L.M.; Dolstra, O.; et al. Extending Miscanthus Cultivation with Novel Germplasm at Six Contrasting Sites. Front. Plant Sci. 2017, 8, 563. [CrossRef] [PubMed]

14. Clifton-Brown, J.C.; Chiang, Y.-C.; Hodkinson, T.R. Miscanthus: Genetic Resources and Breeding Potential to Enhance Bioenergy Production; Springer: New York, NY, USA, 2008.

15. Chung, J.-H.; Kim, D.-S. Miscanthus as a potential bioenergy crop in East Asia. J. Crop. Sci. Biotechnol. 2012, 15, 65-77. [CrossRef]

16. Clark, L.V.; Dzyubenko, E.; Dzyubenko, N.; Bagmet, L.; Sabitov, A.; Chebukin, P.; Yoo, J.H. Ecological characteristics and in situ genetic associations for yield-component traits of wild Miscanthus from eastern Russia. Ann. Bot. 2016, 118, 941-955. [CrossRef]

17. Zub, H.W.; Brancourt-Hulmel, M. Agronomic and physiological performances of different species of Miscanthus, a major energy crop. A review. Agron. Sustain. Dev. 2010, 30, 201-214. [CrossRef] 
18. Jensen, E.; Hastings, A.; Thomas-Jones, S.; Clifton-Brown, J.; Farrar, K.; Donnison, I. Characterization of flowering time diversity in Miscanthus species. GCB Bioenergy 2011, 3, 387-400. [CrossRef]

19. Robson, P.R.H.; Mos, M.; Clifton-Brown, J.; Donnison, I. Phenotypic Variation in Senescence in Miscanthus: Towards Optimising Biomass Quality and Quantity. Bioenergy Res. 2011, 5, 95-105. [CrossRef]

20. Fonteyne, S.; Muylle, H.; Lootens, P.; Kerchev, P.; Ende, W.V.D.; Staelens, A.; Reheul, D.; Roldán-Ruiz, I. Physiological basis of chilling tolerance and early-season growth in miscanthus. Ann. Bot. 2017, 121, 281-295. [CrossRef]

21. Zub, H.W.; Rambaud, C.; Bethencourt, L.; Brancourt-Hulmel, M. Late Emergence and Rapid Growth Maximize the Plant Development of Miscanthus Clones. Bioenergy Res. 2012, 5, 841-854. [CrossRef]

22. Robson, P.R.H.; Farrar, K.; Gay, A.P.; Jensen, E.F.; Clifton-Brown, J.C.; Donnison, I. Variation in canopy duration in the perennial biofuel crop Miscanthus reveals complex associations with yield. J. Exp. Bot. 2013, 64, 2373-2383. [CrossRef] [PubMed]

23. Robson, P.R.H.; Jensen, E.; Hawkins, S.; White, S.R.; Kenobi, K.; Clifton-Brown, J.; Donnison, I.; Farrar, K. Accelerating the domestication of a bioenergy crop: Identifying and modelling morphological targets for sustainable yield increase in Miscanthus. J. Exp. Bot. 2013, 64, 4143-4155. [CrossRef] [PubMed]

24. Weng, J.H. Photosynthesis of different ecotypes of Miscanthus spp. as affected by water stress. Photosynthetica 1994, 29, 43-48.

25. Clifton-Brown, J.; Lewandowski, I.; Bangerth, F.; Jones, M. Comparative responses to water stress in stay-green, rapid-and slow senescing genotypes of the biomass crop, Miscanthus. New Phytol. 2002, 154, 335-345. [CrossRef]

26. Ings, J.; Mur, L.A.J.; Robson, P.R.H.; Bosch, M. Physiological and growth responses to water deficit in the bioenergy crop Miscanthus $\times$ giganteus. Front. Plant Sci. 2013, 4, 468. [CrossRef] [PubMed]

27. Mann, J.J.; Barney, J.N.; Kyser, G.B.; Di Tomaso, J.M. Miscanthus $\times$ giganteus and Arundo donax shoot and rhizome tolerance of extreme moisture stress. GCB Bioenergy 2013, 5, 693-700. [CrossRef]

28. Van Der Weijde, T.; Huxley, L.M.; Hawkins, S.; Sembiring, E.H.; Farrar, K.; Dolstra, O.; Visser, R.G.F.; Trindade, L.M.; Der Weijde, T. Impact of drought stress on growth and quality of miscanthus for biofuel production. GCB Bioenergy 2016, 9, 770-782. [CrossRef]

29. Stavridou, E.; Webster, R.; Robson, P.R.H. Novel Miscanthus genotypes selected for different drought tolerance phenotypes show enhanced tolerance across combinations of salinity and drought treatments. Ann. Bot. 2019, 124, 653-674. [CrossRef]

30. Malinowska, M.; Donnison, I.; Robson, P.R.H. Phenomics analysis of drought responses in Miscanthus collected from different geographical locations. GCB Bioenergy 2016, 9, 78-91. [CrossRef]

31. Greef, J.M.; Deuter, M. Syntaxonomy of Miscanthus $\times$ Giganteus Greef-Et-Deu. Angew. Bot. 1993, 67, 87-90.

32. Lewandowski, I.; Clifton-Brown, J.; Scurlock, J.; Huisman, W. Miscanthus: European experience with a novel energy crop. Biomass Bioenergy 2000, 19, 209-227. [CrossRef]

33. Polak, A.; Wallach, R. Analysis of soil moisture variations in an irrigated orchard root zone. Plant Soil 2001, 233, 145-159. [CrossRef]

34. Clifton-Brown, J.; Lewandowski, I. Water Use Efficiency and Biomass Partitioning of Three Dfferent Miscanthus Genotypes with Limited and Unlimited Water Supply. Ann. Bot. 2000, 86, 191-200. [CrossRef]

35. Correia, M.J.; Rodrigues, M.L.; Ferreira, M.I.; Pereira, J.S. Diurnal change in the relationship between stomatal conductance and abscisic acid in the xylem sap of field-grown peach trees. J. Exp. Bot. 1997, 48, 1727-1736. [CrossRef]

36. Tardieu, F.; Simonneau, T. Variability among species of stomatal control under fluctuating soil water status and evaporative demand: Modelling isohydric and anisohydric behaviours. J. Exp. Bot. 1998, 49, 419-432. [CrossRef]

37. Morison, J.; Baker, N.; Mullineaux, P.; Davies, W. Improving water use in crop production. Philos. Trans. R. Soc. B Boil. Sci. 2007, 363, 639-658. [CrossRef]

38. Richards, R. Crop improvement for temperate Australia: Future opportunities. Field Crop. Res. 1991, 26, 141-169. [CrossRef]

39. Valladares, F.; Martínez-Ferri, E.; Balaguer, L.; Pérez-Corona, M.E.; Manrique, E. Low leaf-level response to light and nutrients in Mediterranean evergreen oaks: A conservative resource-use strategy? New Phytol. 2000, 148, 79-91. [CrossRef] 
40. Thiry, A.; Dulanto, P.N.C.; Reynolds, M.P.; Davies, W.J. How can we improve crop genotypes to increase stress resilience and productivity in a future climate? A new crop screening method based on productivity and resistance to abiotic stress. J. Exp. Bot. 2016, 67, 5593-5603. [CrossRef]

41. Fischer, R.A.; Maurer O, R. Crop Temperature Modification and Yield Potential in a Dwarf Spring Wheat. Crop. Sci. 1976, 16, 855-859. [CrossRef]

42. Fernandez, G.C.J. Effective selection criteria for assessing plant stress tolerance. In Proceeding of the International Symposium on Adaptation of Vegetables and other Food Crops in Temperature and Water Stress, Shanhua, Taiwan, 13-16 August 1992; pp. 257-270.

43. McCaig, T.N.; Clarke, J.M. Seasonal Changes in Nonstructural Carbohydrate Levels of Wheat and Oats Grown in a Semiarid Environment. Crop. Sci. 1982, 22, 963-970. [CrossRef]

44. Clarke, J.M.; Depauw, R.M.; Townley-Smith, T.F. Evaluation of Methods for Quantification of Drought Tolerance in Wheat. Crop. Sci. 1992, 32, 723-728. [CrossRef]

45. Wood, S.N. Stable and Efficient Multiple Smoothing Parameter Estimation for Generalized Additive Models. J. Am. Stat. Assoc. 2004, 99, 673-686. [CrossRef]

46. Hurtado, P.X.; Schnabel, S.K.; Zaban, A.; Veteläinen, M.; Virtanen, E.; Eilers, P.H.C.; Van Eeuwijk, F.A.; Visser, R.G.F.; Maliepaard, C. Dynamics of senescence-related QTLs in potato. Euphytica 2011, 183, $289-302$. [CrossRef]

47. R Core Team. R: A Language and Environment for Statistical Computing; Version 3.2.1; R Foundation for Statistical Computing: Vienna, Austria; Available online: http://www.r-project.org/ (accessed on 10 July 2015).

48. Bartoń, K. MuMIn: Multi-Model Inference, 2015-07-R Package Version 1.14. Available online: http: //cran.r-project.org/web/packages/MuMIn/ (accessed on 10 July 2015).

49. Richards, S.A. Dealing with overdispersed count data in applied ecology. J. Appl. Ecol. 2007, 45, $218-227$. [CrossRef]

50. Bates, D.M.; Machler, M.B.; Bolker, B.M.; Walker, S. Fitting Linear Mixed-Effects Models Using lme. J. Stat. Softw. 2015, 67, 1-48. [CrossRef]

51. Bolker, B.M.; Brooks, M.E.; Clark, C.J.; Geange, S.W.; Poulsen, J.R.; Stevens, M.H.H.; White, J.-S.S. Generalized linear mixed models: A practical guide for ecology and evolution. Trends Ecol. Evol. 2009, 24, 127-135. [CrossRef]

52. DeWitt, T.J.; Sih, A.; Wilson, D.S. Costs and limits of phenotypic plasticity. Trends Ecol. Evol. 1998, $13,77-81$. [CrossRef]

53. Frosman, A. Rethinking phenotypic plasticity and its consequences for individual, population and species. Heredity 2015, 115, 276-284. [CrossRef]

54. Jaleel, C.A.; Manivannan, P.; Wahid, A.; Farooq, M.; Al-Juburi, H.J.; Somasundaram, R. Drought Stress in Plants: A Review on Morphological Characteristics and Pigments Composition. Int. J. Agric. Biol. 2009, 11, 100-105.

55. Chaves, M.M.; Maroco, J.; Pereira, J.S.; Chaves, M.M. Understanding plant responses to drought-From genes to the whole plant. Funct. Plant Boil. 2003, 30, 239-264. [CrossRef] [PubMed]

56. Chaves, M.M.; Flexas, J.; Pinheiro, C. Photosynthesis under drought and salt stress: Regulation mechanisms from whole plant to cell. Ann. Bot. 2008, 103, 551-560. [CrossRef] [PubMed]

57. Cosentino, S.L.; Patanè, C.; Sanzone, E.; Copani, V.; Foti, S. Effects of soil water content and nitrogen supply on the productivity of Miscanthus $\times$ giganteus Greef et Deu. in a Mediterranean environment. Ind. Crop. Prod. 2007, 25, 75-88. [CrossRef]

58. Da Costa, R.; Simister, R.; Roberts, L.A.; Timms-Taravella, E.; Cambler, A.B.; Corke, F.M.K.; Han, J.; Ward, R.J.; Buckeridge, M.S.; Gomez, L.D.; et al. Nutrient and drought stress: Implications for phenology and biomass quality in miscanthus. Ann. Bot. 2018, 124, 553-566. [CrossRef]

59. Poorter, H.; Niklas, K.J.; Reich, P.B.; Oleksyn, J.; Poot, P.; Mommer, L. Biomass allocation to leaves, stems and roots: Meta-analyses of interspecific variation and environmental control. New Phytol. 2011, 193, 30-50. [CrossRef]

60. Chaves, M.M. Effects of Water Deficits on Carbon Assimilation. J. Exp. Bot. 1991, 42, 1-16. [CrossRef]

61. Benešová, M.; Hola, D.; Fischer, L.; Jedelsky, P.L.; Hnilička, F.; Wilhelmová, N.; Rothová, O.; Kocova, M.; Procházkova, D.; Honnerová, J.; et al. The Physiology and Proteomics of Drought Tolerance in Maize: Early Stomatal Closure as a Cause of Lower Tolerance to Short-Term Dehydration? PLoS ONE 2012, 7, e38017. [CrossRef] 
62. Tezara, W.; Mitchell, V.J.; Driscoll, S.D.; Lawlor, D.W. Water stress inhibits plant photosynthesis by decreasing coupling factor and ATP. Nature 1999, 401, 914-917. [CrossRef]

63. Lawlor, D.W.; Cornic, G. Photosynthetic carbon assimilation and associated metabolism in relation to water deficits in higher plants. Plant Cell Environ. 2002, 25, 275-294. [CrossRef]

64. Lawlor, D.W.; Tezara, W. Causes of decreased photosynthetic rate and metabolic capacity in water-deficient leaf cells: A critical evaluation of mechanisms and integration of processes. Ann. Bot. 2009, 103, 561-579. [CrossRef]

65. Granier, C. Water Deficit and Spatial Pattern of Leaf Development. Variability in Responses Can Be Simulated Using a Simple Model of Leaf Development. Plant Physiol. 1999, 119, 609-620. [CrossRef] [PubMed]

66. Zhu, J.K. Salt and drought stress signal transduction in plants. Annu. Rev. Plant Biol. 2002, 53, $247-273$. [CrossRef] [PubMed]

67. Muller, B.; Pantin, F.; Génard, M.; Turc, O.; Freixes, S.; Piques, M.; Gibon, Y. Water deficits uncouple growth from photosynthesis, increase $\mathrm{C}$ content, and modify the relationships between $\mathrm{C}$ and growth in sink organs. J. Exp. Bot. 2011, 62, 1715-1729. [CrossRef] [PubMed]

68. Blum, A. Drought resistance, water-use efficiency, and yield potential-Are they compatible, dissonant, or mutually exclusive? Aust. J. Agric. Res. 2005, 56, 1159-1168. [CrossRef]

69. Condon, A.G.; Richards, R.; Rebetzke, G.; Farquhar, G. Improving intrinsic water use efficiency and crop yield. Crop Sci. 2002, 42, 122-131.

70. Chaves, M.M.; Oliveira, M.M. Mechanisms underlying plant resilience to water deficits: Prospects for water-saving agriculture. J. Exp. Bot. 2004, 55, 2365-2384. [CrossRef]

71. Skirycz, A.; De Bodt, S.; Obata, T.; De Clercq, I.; Claeys, H.; De Rycke, R.; Andriankaja, M.; Van Aken, O.; Van Breusegem, F.; Fernie, A.R.; et al. Developmental Stage Specificity and the Role of Mitochondrial Metabolism in the Response of Arabidopsis Leaves to Prolonged Mild Osmotic Stress. Plant Physiol. 2009, 152, 226-244. [CrossRef]

72. Claeys, H.; Inze, D. The Agony of Choice: How Plants Balance Growth and Survival under Water-Limiting Conditions. Plant Physiol. 2013, 162, 1768-1779. [CrossRef]

73. Hickman, G.C.; Vanloocke, A.; Dohleman, F.G.; Bernacchi, C.J. A comparison of canopy evapotranspiration for maize and two perennial grasses identified as potential bioenergy crops. GCB Bioenergy 2010, 2, 157-168. [CrossRef]

74. Merchant, A.; Callister, A.; Arndt, S.K.; Tausz, M.; Adams, M.A. Contrasting Physiological Responses of Six Eucalyptus Species to Water Deficit. Ann. Bot. 2007, 100, 1507-1515. [CrossRef]

75. Moussa, H.; Abdel-Aziz, S. Comparative response of drought tolerant and drought sensitive maize genotypes to water stress. Aust. J. Crop Sci. 2008, 1, 31-36.

76. Costa, J.M.; Ortuño, M.F.; Lopes, C.M.; Chaves, M.M. Grapevine varieties exhibiting differences in stomatal response to water deficit. Funct. Plant Boil. 2012, 39, 179. [CrossRef] [PubMed]

77. Jeżowski, S. Yield traits of six clones of Miscanthus in the first 3 years following planting in Poland. Ind. Crop. Prod. 2008, 27, 65-68. [CrossRef]

(C) 2020 by the authors. Licensee MDPI, Basel, Switzerland. This article is an open access article distributed under the terms and conditions of the Creative Commons Attribution (CC BY) license (http://creativecommons.org/licenses/by/4.0/). 